\title{
Effects of common variations of NOS3 and CAV1 genes on hypercholesterolemic profile in coronary heart disease
}

\author{
Serap İlikay' (D), Ender Coșkunpınar ${ }^{1}$ (D), Özlem Kurnaz-Gömleksiz² (D), Zehra Buğra ${ }^{3}$ (D), Allison P. Eronat ${ }^{1}$ (D), \\ Oğuz Öztürk' (1), Hülya Yılmaz-Aydoğan ${ }^{* *}$ (i) \\ 'Department of Molecular Medicine, Aziz Sancar Institute of Experimental Medicine, Istanbul University, 34116 Istanbul, Turkey \\ ${ }^{2}$ Department of Medical Biology, Altınbaș University, Faculty of Medicine, Istanbul, Turkey \\ ${ }^{3}$ Department of Cardiology, Istanbul University, Faculty of Medicine, 34116 Istanbul, Turkey
}

ORCID IDs of the authors: S.I. 0000-0002-3752-5930; E.C. 0000-0002-1003-5544; Ö.K.G. 0000-0001-9827-5253; Z.B. 00000002-9904-0146; A.P.E. 0000-0002-8095-1759; 0.0̈. 0000-0002-2439-9269; H.Y.A. 0000-0002-8837-6664.

Cite this article as: Illikay S, Coșkunpınar E, Kurnaz-Gömleksiz Ö, Buğra Z, Eronat AP, Öztürk O, Yılmaz-Aydoğan H (2019). Effects of common variations of NOS3 and CAV1 genes on hypercholesterolemic profile in coronary heart disease. Istanbul J Pharm 49 (2): 53-60.

\section{ABSTRACT}

Caveolin-1 (CAV-1) plays a crucial role in endothelial-nitric oxide synthase (eNOS) enzymatic activity. Therefore, CAV-1 and eNOS interactions have a significant impact on endothelial dysfunction, cholesterol levels, and atherosclerosis. We investigated the critical variations in NOS3 and CAV1 genes in this case-control study to determine the relations between the coronary heart disease (CHD) risk factors. The NOS3-rs1799983, CAV-1 rs3840634, and rs3807990 variations were analyzed in 76 CHD patients and 91 controls using the polymerase chain reaction. Mean serum Total-cholesterol levels were significantly higher in CHD patients with the CAV-1 rs3807990-T allele than in patients with CC genotype ( $p=0.017)$. There was a statistically significant correlation between the rs3807990-T allele and hypercholesterolemia in the CHD group ( $p=0.008$ ). The multivariate analysis confirmed that the CAV- 1 rs3807990-T allele $(p=0.011)$ is a risk factor for hypercholesterolemia. Moreover, the serum HDL-Cholesterol level was detected to be higher in patients carrying both CAV1-rs3807990-T and NOS3-rs1799983-T alleles than those with the CAV-1 rs3807990-CC/ NOS3-rs1799983-GG genotype subgroup ( $p=0.013$ ). These results suggested that the genetic variations of CAV-1 rs3807990 and NOS3-rs1799983 may contribute to the increased hypercholesterolemia risk and thus on the development of CHD.
\end{abstract}

Keywords: Cav1, NOS3, gene, hypercholesterolemia, lipid, CHD

\section{INTRODUCTION}

Coronary heart disease (CHD) was among the leading causes of mortality in worldwide. Endothelial dysfunction plays a central role in atherosclerosis pathogenesis that leads to CHD (Foy and Grant 1997; Hadi and Suwaidi 2007). Main causes of endothelial dysfunction are impaired anticoagulant and antiplatelet mechanisms, increased production of cellular adhesion molecules and increased vascular tone due to reduced bioavailability of endothelial-derived vasodilatory nitric oxide (NO) (Lahera et al. 2007). In the mammalian blood vessels, most of the NO production is mediated by calcium-calmodulin controlled endothelial nitric oxide synthase isoenzyme (eNOS). Caveolin-1 (Cav-1) encoded by the Cav-1 gene (Grilo et al. 2006), is a permanent regulator of the eNOS enzyme activity (Ju et al. 1997; Blair et al. 1999). Cav-1 converts the inactivated form of eNOS by binding directly to the oxygenase domain and Ca+2/CaM activate the eNOS in the endothelial cells (Ju et al. 1997).

Cav-1 is found in macrophages, and endothelial and vascular smooth muscle cells (VSMC) take part in the atherosclerosis process (Couet et al. 1997). A remarkable decrease was observed in the extent of atherosclerotic lesions in a study on ApoE ${ }^{-1-}$ Cav-1\% double knockout mice (Puglielli et al. 1995). In contrast, it was reported that the reduced Cav-1 expression in VSMCs of atheroma, 
which suggested that it might have an anti-atherogenic effect in VSMCs (Williams and Lisanti 2004). Cav-1 functions as a scaffold protein for the organization and activation of proteins such as Src-like kinase, G proteins and eNOS in caveolae membrane (Marsden et al. 1993; Chen et al. 1996). It was shown that Cav-1 may cause atherosclerosis by inactivating eNOS in endothelial cells in several experiments on mice. Endothelial nitric oxide synthase enzyme encoded by the NOS3 gene has " $\mathrm{N}$ terminal oxygenase" and "C-terminal reductase" domains and the $\mathrm{Ca}^{+2} /$ calmodulin (CaM) binding region is located between these two domains (Venema et al. 1996; Yoshimura et al. 1998).

Cav-1 and caveolae also have roles in maintaining cholesterol homeostasis. While Cav-1 interacts with the sterol carrier protein-2 (SCP-2) involved in the delivery of newly produced cholesterol from the smooth endoplasmic reticulum to the cell membrane (Chen et al. 1996; Lusis 2000), caveolae are effective in taking the released free cholesterol to plasma by the HDL and cholesterol esters from plasma (Frank and Lisanti 2004). Both the amino-terminal and carboxy-terminal cytoplasmic regions of Cav-1 and the oxygenase domain of eNOS are involved in this interaction. Recent studies have reported that the deficiency of Cav-1 in endothelial cells (ECs) impairs LDL transendothelial migration. Therefore, the pro-atherogenic effects of Cav-1 in endothelial cells are mainly attributed to its effects on LDL transcytosis. Unlike ECs, Cav-1 deficiency in macrophages causes the foam cells formation by stimulating the accumulation of cholesterol esters. This observation suggests that it has an antiatherogenic effect (Hassan et al. 2004). Therefore, it was suggested that the Cav-1 had differently influenced the development of atherosclerotic vascular disease depending on cell type and metabolic pathway.

Studies regarding the association between the Cav-1 gene variants with cardiovascular diseases and lipid metabolism are scarce (Chen et al. 2005; Schwencke et al. 2005; Carey et al. 2012). Chen et al. 2005, reported that rs3807989 at the Cav-1/Cav-2 locus was associated with significant risk of coronary artery disease (CAD) and myocardial infarction (MI) by increasing Cav-1 expression. They also suggested that "A" allele of the CAV1 rs3807989 gene is correlated with a decreased LDL cholesterol level.

There is transversion mutation (G>T) at nucleotide 1917 in exon 7 of the NOS3 gene, causing the glutamic acid to aspartic acid substitution at codon 298 (Glu298Asp, rs 1799983) (Huang et al. 1995; Conde et al. 2006). The Glu298Asp mutation has been shown to be related to atherosclerotic coronary events (Huang et al. 1996; Freedman et al. 1999; Lefer et al. 1999; Huang 2000). Although the interactions of Cav-1 and eNOS activity have been shown in previous studies (Chen et al. 1996; Venema et al. 1996), there are limited studies concerning the association of the genetic alterations in these genes. Joshi et al. have shown that the Cav-1 - NOS3 complex is dissociated to notably much more in the Glu/Glu wild type ECs than in the Asp variants. They suggested that NOS3 Glu298Asp variation changed caveolar localization and damaged endothelial response to shear in human endothelium (Joshi et al. 2007).

In a recent study, the rs3840634 (2 bp deletion) and rs3807990 C>T variants of Cav-1 together with NOS3 rs1799983 were shown to be related to colorectal cancer susceptibility (Conde et al. 2006). Shyu et al. (2017) demonstrated the minor alleles of genotypic polymorphisms of the NOS3 rs1799983 G>T (Glu298Asp), Cav-1 rs3807987 G>A and rs7804372 T>A are related to the increased stroke risk of large artery among Han Chinese. Due to the relationship between Cav-1 and eNOS, we suggest that functional genetic variations of these proteins could be an important risk factor for cardiovascular events. Thus, the aim of this study was to examine the association between the NOS3-rs1799983, Cav-1 rs3840634, and rs3807990 gene variations and the risk of $\mathrm{CHD}$ with respect to both of individual and combined effects of lipid profiles and the other atherosclerotic risk factors in the Turkish population. Regarding Cav-1, this is the first study investigating the effects of the Cav-1 rs3807990 SNP on risk parameters in CHD patients.

\section{MATERIALS AND METHODS}

\section{Subjects}

This study was a case-control investigation. Control group consisted of 91 healthy individuals with no family history and any signs of diabetes mellitus, renal failure, hypertension, or dyslipidemia. The patient group consisted of 76 patients diagnosed with coronary heart disease followed by the Department of Cardiology, İstanbul University Faculty of Medicine between the period from 2013 to 2014. All the patients were receiving statin for lipid-lowering effects based on conventional therapy.

Criteria for angiography were $50 \%$ stenosis at least in one main coronary artery caused by atherosclerosis, and a vascular case, described as myocardial infarction, percutaneous transluminal coronary angioplasty, or coronary artery bypass grafting. All subjects gave the answers for the full histories with special emphasis on coronary risk factors like family history, diabetes mellitus, hyperlipidemia, hypertension, and smoking. Percentages of patients with hypertension, type 2 diabetes and left ventricular hypertrophy were $43.4 \%, 43.4 \%$, and $39.6 \%$, respectively.

This study was arranged in accordance with the "World Medical Association Declaration of Helsinki" and written consents were obtained from all participants. This study was authorized by the Ethics Committees of the Faculty of Medicine, İstanbul University.

\section{Genotyping}

Genomic DNA was isolated from the peripheral blood samples collected in EDTA tubes by using a DNA isolation kit (Roche Diagnostics GmbH, Mannheim, Germany). CAV1 rs3840634 (AC deletion) genotyping was carried out by LightCycler real-time PCR (Roche, Germany) via commercial LightSNiP assays from TIB-MolBiol (Germany), in accordance with the company's procedures. Melting curve analysis of the PCR products qualified the genotypes of the rs3840634 as homozygote major allele (TT), heterozygote (CT) and homozygote minor allele (CC). Tm values were 56.98 and 63.77 for the T and C alleles, respectively.

Cav-1 rs3807990 (C>T) and NOS3 rs1799983 (G>T) polymorphisms were determined by the Polymerase Chain ReactionRestriction Fragment Length Polymorphism (PCR-RFLP) method using the Mspl and Banll restriction enzymes, respectively. Mspl 
Table 1. Characteristics of the study groups

\begin{tabular}{lccc} 
& Control $n=91$ & CHD $n=76$ & 0.822 \\
\hline Age (year) & $59.10 \pm 9.85$ & $59.49 \pm 12.38$ & 0.175 \\
Sex (Women/Men) (n) & $38 / 53$ & $24 / 52$ & 0.003 \\
SBP (mmHg) & $123.99 \pm 12.27$ & $135.95 \pm 32.38$ & 0.0041 \\
DBP (mmHg) & $73.91 \pm 8.54$ & $83.99 \pm 17.18$ & 0.003 \\
TC (mmol/L) & $4.72 \pm 0.96$ & $5.28 \pm 1.40$ & 0.123 \\
TG (mmol/L) & $1.45 \pm 0.66$ & $1.77 \pm 1.80$ & 0.001 \\
HDL-C(mmol/L) & $1.22 \pm 0.34$ & $1.03 \pm 0.21$ & 0.006 \\
LDL-C (mmol/L) & $2.86 \pm 0.87$ & $3.23 \pm 0.81$ & 0.819 \\
VLDL-C (mmol/L) & $0.71 \pm 0.39$ & $0.72 \pm 0.32$ & 0.669 \\
BMI (kg/m2) & $25.83 \pm 2.33$ & $25.58 \pm 4.20$ & 0.001 \\
Smoking (\%) & $21.8 \%$ & $59.5 \%$ & 0.030 \\
Alcohol consumption (\%) & $4.7 \%$ & $16.7 \%$ & 0.285 \\
CHD Family history (\%) & $21.7 \%$ & $33.9 \%$ & \\
\hline Valus we & & 0 \\
\hline
\end{tabular}

Values were derived by using independent-samples. The results are shown as mean \pm SD. Bold values of $p$ indicates statistical significance. TC, total cholesterol; TG, triglyceride; HDL-C, HDL-cholesterol; LDL-C, LDL-cholesterol; VLDL-C, VLDL-cholesterol; TC/HDL-C, total cholesterol/ HDL-cholesterol; BMI, body mass index; SBP, systolic blood pressure; DBP, diastolic blood pressure; $n$, number of individuals.

\section{Table 2. Genotype distributions of the CAV1 and NOS3 variations in the study groups}

\begin{tabular}{|c|c|c|c|}
\hline \multicolumn{2}{|c|}{ CAV1 and NOS3 variatio } & \multicolumn{2}{|c|}{ Study Groups } \\
\hline $\begin{array}{l}\text { CAV1 } \\
\text { rs3807990 }\end{array}$ & & $\begin{array}{l}\text { Controls } \\
(n=91)\end{array}$ & $\begin{array}{c}\text { CHD patients } \\
(n=73)\end{array}$ \\
\hline \multirow[t]{4}{*}{ Genotypes } & $\mathrm{CC}$ & $49(53.8 \%)$ & $46(63 \%)$ \\
\hline & TT & $8(8.8 \%)$ & $5(6.8 \%)$ \\
\hline & CT & $34(37.4 \%)$ & $22(30.1 \%)$ \\
\hline & HWE & $p=0.552(p>0.05)$ & $p=0.300(p>0.05$ \\
\hline \multirow[t]{2}{*}{ Alleles } & C & $132(72.5 \%)$ & $114(78.1 \%)$ \\
\hline & $\mathrm{T}$ & $50(27.5 \%)$ & $32(21.9 \%)$ \\
\hline \multicolumn{4}{|c|}{ CAV1 rs3840634 } \\
\hline \multirow[t]{4}{*}{ Genotypes } & TT & $91(100 \%)$ & $73(100 \%)$ \\
\hline & $\mathrm{CC}$ & $0(0 \%)$ & $0(0 \%)$ \\
\hline & CT & $0(0 \%)$ & $0(0 \%)$ \\
\hline & HWE & Uncountable & Uncountable \\
\hline
\end{tabular}

NOS3 rs1799983

$\begin{array}{llcc}\text { Genotypes } & \text { GG } & 44(48.35 \%) & 33(44 \%) \\ & \text { TT } & 7(7,69 \%) & 8(10.7 \%) \\ & \text { GT } & 40(43.96 \%) & 32(45.3 \%) \\ \text { Alleles } & \text { HWE } & p=0.726(p>0.05) & p=0.826(p>0.05) \\ & \text { G } & 122(67.03 \%) & 98(67.12 \%) \\ & \text { T } & 54(29.67 \%) & 48(32.88 \%)\end{array}$

n: number of samples, HWE: Hardy-Weinberg Disequilibrium.

digestion resulted in fragments of 122 and $121 \mathrm{bp}$ for the $C$ allele of CAV1 rs3807990 (C>T). PCR product of the CAV1 rs3807990 (C>T) (243 bp) was not digested with Mspl in the presence of the T allele. The NOS3 gene rs1799983 (G>T) Glu298Asp missense mutation causes a Banll recognition site, that digests the PCR product to fragments of 198 and $122 \mathrm{bp}$ in the presence of the $\mathrm{G}$ allele and a single fragment of $320 \mathrm{bp}$ for the $T$ allele. The digestion products were separated by $3 \%$ agarose gel elec- trophoresis. Homozygous normal GG genotype had two bands (198 and 122 bp) while the homozygous mutant TT genotype had a 320 bp band after visualized under UV. Heterozygous GT genotype has three bands like 320 bp, 198 bp, and 122 bp.

\section{Statistical Analysis}

The Statistical Package for the Social Sciences (SPSS) software package version 20.0, (IBM Corp., Armonk, NY, USA) was used for all statistical analyses. Values of $\mathrm{p}<0.05$ were accepted statistically significant. The odds ratio and 95\% confidence interval were worked out to examine relative risks among the study groups. Comparing the quantitative data among groups were carried out by applying Student's t-Test and ANOVA test, for more than two variables. Compatibility with the Hardy-Weinberg equilibrium (HWE) of the comparisons of genotype and allele were analyzed by chi-square test. Gene counting methods were used for calculating the allele frequencies.

The Binary logistic regression analysis was used to assess the effects of the CAV1 rs3807990 SNP on hypercholesterolemia in patients with CHD (Table 6). In the regression analysis, the CAV1 rs3807990 SNP T allele, sex, and Type 2 Diabetes mellitus and smoking were used as independent variables. The multivariate regression model including hypercholesterolemia status as the dependent variable was used.

\section{RESULTS}

\section{Clinical Investigation}

Demographic and biochemical characteristics of the study groups are given in Table 1. As expected, the CHD group had a higher prevalence of conventional cardiovascular diseases risk factors such as systolic blood pressure (SBP) $(p=0.003)$, diastolic blood pressure (DBP) $(p<0.001)$, Total-cholesterol (Total-C) $(p=0.003)$, LDL-cholesterol (LDL-C) $(p=0.006)$, smoking $(p<0.001)$ and alcohol consumption $(p=0.03)$ and lower HDLcholesterol (HDL-C) levels ( $p<0.001)$. There were no statistical differences in age, sex, body mass index (BMI), triglyceride and 
VLDL-cholesterol (VLDL-C) levels and family history of CHD between the patient and control groups ( $p>0.05)$.

\section{Distributions and Metabolic Effects CAV1 rs3807990 and NOS3 rs1799983 Genotypes}

As shown in Table 2, the Cav-1 rs3807990 and NOS3 rs1799983 gene variations were concordant with HWE in both groups ( $p>0.05)$. We also analyzed the Cav-1 gene rs3840634 AC deletion. However, the rare C allele of the Cav-1 rs3840634 was not found in either group and all individuals were carrying the normal TT genotype. Therefore, compliance with HWE was not evaluated for the Cav-1 rs3840634 variants.

When the effects of the Cav-1 rs3807990 genotypes on serum lipid profile, BMI, and blood pressures were investigated in study groups, BMI levels were higher in individuals with the CT genotypes than with the TT genotype in the control group $(p=0.046)$ and DBP value was lower in Cav-1 rs3807990 normal C allele carriers than in non-carriers (TT genotype) (C allele: $73.42 \pm 8.65$, TT genotype: $79.67 \pm 4.32, p=0.014$ ) (Table 3 ). In the patient group, CT genotype carriers had higher serum Total-C levels than CC genotype carriers ( $p=0.008$, one way Anova test) (Table 3 ). In addition, it was found that Total-C were higher in patients with the T allele than in those with the CC genotype ( $T$ allele: $5.78 \pm 1.88$, CC genotype: 4.98 $\pm 0.90, p=0.017$, Student's t test) (Table 3). Therefore, increased levels of Total-C observed in the patients carrying the CT genotype can be attributed to the T allele.
When the effects of the NOS3 rs1799983 genotypes on serum lipid profile, BMI, and blood pressures in the study groups were examined, BMI value was found to be higher in controls with the TT genotype as compared to the GG and GT genotype carriers $(p=0.003)$ and $G$ allele carriers $(p=0.002)$. However, in the patient group, there were no statistically important effects of the NOS3 rs1799983 genotypes on clinical or biochemical parameters ( $p>0.05$ ) (Table 4).

The combined effects of Cav-1 rs3807990 and NOS3 rs1799983 genotypes were also evaluated on serum lipids, BMI, and blood pressures which are given in Table 5. In CHD patients with the Cav-1 rs3807990 rare T allele and the NOS3 rs1799983 rare $\mathrm{T}$ allele higher HDL-C levels were observed than patients with the common genotypes of Cav-1 rs3807990 (CC) / NOS3 rs1799983 (GG) (1.12 \pm 0.12 vs. $1.01 \pm 0.22, p=0.013)$. There were no significant differences found among the rare $T$ alleles of Cav-1 rs3807990 / NOS3 rs1799983 haplotype and the Cav-1 rs3807990 CC/NOS3 rs1799983 GG haplotype in terms of serum lipid profile in the controls ( $p>0.05$ ).

The association between the Cav-1 rs3807990 SNP and hypercholesterolemia (serum Total-C above $5.18 \mathrm{mmol} / \mathrm{L}$ ) in the patients with CHD is shown in Figure 1. A significant association was observed between the rs3807990 rare T allele and hypercholesterolemia (chi-square $=6.951, p=0.008$ ). However, we didn't observe any effect of this SNP on hypercholesterolemia in the controls ( $p=0.161)$, as it was observed in CHD patients.

Table 3. Metabolic parameters for the CAV-1 rs3807990 genotypes among study groups

\begin{tabular}{|c|c|c|c|c|c|}
\hline \multirow[t]{2}{*}{ Groups } & \multicolumn{5}{|c|}{ rs3807990 } \\
\hline & $\mathrm{CC}$ & CT & TT & $\mathrm{C}$ allele $(\mathrm{CC}+\mathrm{CT})$ & $\mathrm{T}$ allele $(\mathrm{TT}+\mathrm{CT})$ \\
\hline Control & $n=49$ & $n=34$ & $\mathrm{n}=8$ & $n=83$ & $n=42$ \\
\hline Age & $59.78 \pm 10.36$ & $58.71 \pm 9.60$ & $56.63 \pm 8.02$ & $59.34 \pm 10.01$ & $58.31 \pm 9.27$ \\
\hline Glucose & $94.64 \pm 10.10$ & $96.94 \pm 12.19$ & $105.00 \pm 7.55$ & $95.48 \pm 10.85$ & $98.04 \pm 11.87$ \\
\hline Total-C (mmol/L) & $4.66 \pm 1.06$ & $4.84 \pm 0.88$ & $4.59 \pm 0.61$ & $4.74 \pm 0.99$ & $4.80 \pm 0.84$ \\
\hline TG (mmol/L) & $1.38 \pm 0.55$ & $1.57 \pm 0.80$ & $1.41 \pm 0.62$ & $1.46 \pm 0.66$ & $1.54 \pm 0.77$ \\
\hline HDL-C (mmol/L) & $1.20 \pm 0.28$ & $1.19 \pm 0.36$ & $1.42 \pm 0.52$ & $1.20 \pm 0.31$ & $1.23 \pm 0.40$ \\
\hline LDL -C(mmol/L) & $2.79 \pm 0.91$ & $3.03 \pm 0.84$ & $2.47 \pm 0.56$ & $2.89 \pm 0.88$ & $2.93 \pm 0.82$ \\
\hline VLDL-C(mmol/L) & $0.69 \pm 0.42$ & $0.74 \pm 0.38$ & $0.70 \pm 0.34$ & $0.71 \pm 0.40$ & $0.73 \pm 0.37$ \\
\hline BMI (kg/m2) & $25.94 \pm 1.96$ & $26.05 \pm 2.51 *$ & $24.23 \pm 3.17$ & $25.99 \pm 2.19$ & $25.71 \pm 2.71$ \\
\hline $\mathrm{SBP}(\mathrm{mmHg})$ & $123.29 \pm 12.84$ & $125.27 \pm 12.11$ & $122.67 \pm 9.93$ & $124.09 \pm 12.50$ & $124.83 \pm 11.67$ \\
\hline $\mathrm{DBP}(\mathrm{mmHg})$ & $73.02 \pm 7.50$ & $74.00 \pm 10.19$ & $79.67 \pm 4.32$ & $73.42 \pm 8.65 ¥$ & $74.97 \pm 9.65$ \\
\hline CHD Patients & $\mathrm{n}=46$ & $n=22$ & $n=5$ & $\mathrm{n}=68$ & $\mathrm{n}=27$ \\
\hline Age & $61.46 \pm 10.75$ & $58.50 \pm 14.30$ & $54.60 \pm 15.82$ & $60.50 \pm 11.99$ & $57.78 \pm 14.35$ \\
\hline Glucose & $179.35 \pm 121.15$ & $174.72 \pm 130.63$ & $223.33 \pm 184.81$ & $177.83 \pm 123.13$ & $181.67 \pm 134.99$ \\
\hline Total-C (mmol/L) & $4.98 \pm 0.90$ & $5.92 \pm 2.04 \&$ & $5.13 \pm 0.63$ & $5.29 \pm 1.43$ & $5.78 \pm 1.89 \sum$ \\
\hline TG (mmol/L) & $1.55 \pm 0.67$ & $2.23 \pm 3.13$ & $1.89 \pm 1.10$ & $1.77 \pm 1.9$ & $2.16 \pm 2.85$ \\
\hline $\mathrm{HDL}-\mathrm{C}$ (mmol/L) & $1.03 \pm 0.20$ & $1.06 \pm 0.16$ & $1.12 \pm 0.21$ & $1.04 \pm 0.19$ & $1.07 \pm 0.17$ \\
\hline LDL -C(mmol/L) & $3.07 \pm 0.82$ & $3.47 \pm 0.69 \#$ & $3.33 \pm 0.81$ & $3.20 \pm 0.79$ & $3.44 \pm 0.70 \Omega$ \\
\hline VLDL-C(mmol/L) & $0.72 \pm 0.31$ & $0.72 \pm 0.30$ & $0.72 \pm 0.49$ & $0.72 \pm 0.30$ & $0.72 \pm 0.34$ \\
\hline BMI (kg/m²) & $25.75 \pm 4.07$ & $24.96 \pm 3.43$ & $22.91 \pm 3.70$ & $25.47 \pm 3.85$ & $24.52 \pm 3.51$ \\
\hline $\mathrm{SBP}(\mathrm{mmHg})$ & $133.64 \pm 25.78$ & $145.0 \pm 41.94$ & $116.0 \pm 37.82$ & $137.42 \pm 32.30$ & $139.62 \pm 42.10$ \\
\hline $\mathrm{DBP}(\mathrm{mmHg})$ & $82.84 \pm 17.13$ & $88.41 \pm 17.42$ & $74.0 \pm 15.17$ & $84.69 \pm 17.29$ & $85.74 \pm 17.68$ \\
\hline
\end{tabular}




\begin{tabular}{|c|c|c|c|c|c|}
\hline \multirow[t]{2}{*}{ GROUPS } & \multicolumn{5}{|c|}{ rs1799983 } \\
\hline & GG & GT & TT & GG/GT & $\mathrm{TT} / \mathrm{GT}$ \\
\hline CONTROL & $n=44$ & $n=40$ & $\mathrm{n}=7$ & $n=84$ & $n=47$ \\
\hline Age & $58.49 \pm 9.96$ & $59.66 \pm 9.66$ & $56.67 \pm 12.48$ & $59.04 \pm 9.76$ & $59.18 \pm 10.02$ \\
\hline Glucose & $97.06 \pm 11.96$ & $94.73 \pm 12.62$ & $99.00 \pm 7.53$ & $95.80 \pm 12.20$ & $95.48 \pm 11.87$ \\
\hline Total-C & $4.65 \pm 1.15$ & $4.80 \pm 0.64$ & $4.95 \pm 1.00$ & $4.72 \pm 0.94$ & $4.82 \pm 0.69$ \\
\hline TG & $1.35 \pm 0.49$ & $1.48 \pm 0.78$ & $1.36 \pm 0.81$ & $1.41 \pm 0.64$ & $1.46 \pm 0.76$ \\
\hline HDL-C & $1.29 \pm 0.35$ & $1.20 \pm 0.38$ & $1.15 \pm 0.31$ & $1.25 \pm 0.36$ & $1.19 \pm 0.37$ \\
\hline LDL -C & $2.84 \pm 0.99$ & $2.94 \pm 0.62$ & $2.80 \pm 0.95$ & $2.89 \pm 0.83$ & $2.91 \pm 0.67$ \\
\hline VLDL -C & $0.62 \pm 0.25$ & $0.74 \pm 0.42$ & $0.85 \pm 0.82$ & $0.67 \pm 0.34$ & $0.76 \pm 0.49$ \\
\hline BMI & $25.44 \pm 1.99$ & $25.35 \pm 2.70$ & $28.59 \pm 2.19 *$ & $25.40 \pm 2.34 ¥$ & $25.86 \pm 2.89$ \\
\hline SBP & $122.72 \pm 11.80$ & $125.13 \pm 13.14$ & $113.60 \pm 10.71$ & $120.03 \pm 12.50$ & $123.48 \pm 13.33$ \\
\hline DBP & $72.40 \pm 7.65$ & $77.03 \pm 9.37$ & $72.60 \pm 9.15$ & $74.92 \pm 8.86$ & $76.40 \pm 9.34$ \\
\hline CHD PATIENTS & $n=33$ & $n=32$ & $\mathrm{n}=8$ & $n=65$ & $n=40$ \\
\hline Age & $61.09 \pm 11.84$ & $59.24 \pm 13.63$ & $56.38 \pm 6.93$ & $60.15 \pm 12.72$ & $58.69 \pm 12.61$ \\
\hline Glucose & $194.48 \pm 134.92$ & $191.19 \pm 140.49$ & $135.50 \pm 71.01$ & $192.86 \pm 136.36$ & $180.75 \pm 131.22$ \\
\hline Total-C & $5.29 \pm 1.64$ & $5.24 \pm 1.27$ & $5.35 \pm 1.07$ & $5.27 \pm 1.45$ & $5.27 \pm 1.23$ \\
\hline TG & $1.65 \pm 0.81$ & $1.94 \pm 2.54$ & $1.50 \pm 0.67$ & $1.80 \pm 1.90$ & $1.85 \pm 2.31$ \\
\hline HDL-C & $1.01 \pm 0.23$ & $1.05 \pm 0.19$ & $1.12 \pm 0.17$ & $1.02 \pm 0.21$ & $1.06 \pm 0.18$ \\
\hline LDL -C & $3.26 \pm 0.95$ & $3.20 \pm 0.72$ & $3.15 \pm 0.59$ & $3.23 \pm 0.84$ & $3.19 \pm 0.69$ \\
\hline VLDL -C & $0.74 \pm 0.36$ & $0.68 \pm 0.27$ & $0.75 \pm 0.34$ & $0.72 \pm 0.32$ & $0.70 \pm 0.28$ \\
\hline BMI & $26.16 \pm 4.48$ & $24.98 \pm 4.00$ & $26.46 \pm 4.03$ & $25.53 \pm 4.23$ & $25.32 \pm 4.00$ \\
\hline SBP & $142.34 \pm 31.90$ & $134.09 \pm 33.66$ & $121.25 \pm 26.42$ & $138.15 \pm 32.82$ & $131.59 \pm 32.49$ \\
\hline DBP & $86,72 \pm 16,29$ & $83,18 \pm 16,85$ & $78,13 \pm 22,35$ & $84,92 \pm 16,55$ & $82,20 \pm 17,86$ \\
\hline
\end{tabular}

Table 5. Combined effects of CAV-1 rs3807990 and NOS3 rs1799983 on metabolic parameters

\begin{tabular}{|c|c|c|c|}
\hline \multirow[t]{2}{*}{ GROUPS } & \multicolumn{2}{|c|}{ CAV-1 rs3807990 and NOS3 rs1799983 Haplotypes } & \multirow[b]{2}{*}{$P$ value } \\
\hline & eNOS T allele/CAV-1 T allele & eNOS GG/CAV-1 CC & \\
\hline CONTROL & $\mathrm{n}=22$ & $\mathrm{n}=69$ & \\
\hline Glucose (mg/dL) & $99.36 \pm 13.37$ & $95.05 \pm 10.07$ & 0.250 \\
\hline Total-C (mmol/L) & $4.77 \pm 0.66$ & $4.75 \pm 1.04$ & 0.943 \\
\hline TG (mmol/L) & $1.62 \pm 0.91$ & $1.39 \pm 0.54$ & 0.288 \\
\hline HDL-C (mmol/L) & $1.19 \pm 0.44$ & $1.23 \pm 0.30$ & 0.586 \\
\hline LDL -C(mmol/L) & $2.91 \pm 0.62$ & $2.89 \pm 0.94$ & 0.920 \\
\hline VLDL -C(mmol/L) & $0.79 \pm 0.43$ & $0.68 \pm 0.39$ & 0.293 \\
\hline BMI $(\mathrm{kg} / \mathrm{m} 2)$ & $25.27 \pm 3.14$ & $25.87 \pm 2.01$ & 0.432 \\
\hline $\mathrm{SBP}(\mathrm{mmHg})$ & $126.26 \pm 14.77$ & $123.27 \pm 11.81$ & 0.380 \\
\hline $\mathrm{DBP}(\mathrm{mmHg})$ & $76.53 \pm 10.94$ & $73.65 \pm 7.29$ & 0.206 \\
\hline CHD PATIENTS & $n=16$ & $n=56$ & \\
\hline Glucose (mg/dL) & $194.75 \pm 141.84$ & $186.02 \pm 132.13$ & 0.842 \\
\hline Total-C (mmol/L) & $5.81 \pm 1.60$ & $5.12 \pm 1.34$ & 0.084 \\
\hline TG (mmol/L) & $2.44 \pm 3.66$ & $1.57 \pm 0.71$ & 0.357 \\
\hline HDL-C (mmol/L) & $1.12 \pm 0.12$ & $1.01 \pm 0.22$ & 0.013 \\
\hline LDL -C(mmol/L) & $3.53 \pm 0.64$ & $3.13 \pm 0.84$ & 0.089 \\
\hline VLDL -C(mmol/L) & $0.70 \pm 0.32$ & $0.71 \pm 0.32$ & 0.885 \\
\hline BMI (kg/m2) & $25.25 \pm 3.62$ & $25.75 \pm 4.43$ & 0.693 \\
\hline $\mathrm{SBP}(\mathrm{mmHg})$ & $129.38 \pm 39.41$ & $139.75 \pm 30.38$ & 0.313 \\
\hline DBP $(\mathrm{mmHg})$ & $81.56 \pm 18.05$ & $85.27 \pm 17.01$ & 0.451 \\
\hline
\end{tabular}




\section{Table 6. Evaluation of risk factors associated with hypercholesterolemia by Binary logistic regression analysis in CHD patients}

\begin{tabular}{|lccccc|} 
Variables & p value & B & SE & Exp (B) & OR (95\% Cl) for Exp (B) \\
\hline Sex & 0.353 & 0.582 & 0.627 & 1.790 & $0.524-6.114$ \\
Type 2 Diabetes mellitus & 0.480 & -0.448 & 0.553 & 0.639 & $0.184-2.217$ \\
Smoking & 0.850 & 0.133 & 0.700 & 1.142 & $0.290-4.504$ \\
CAV1 rs3807990 T Allele & 0.011 & -1.412 & 0.726 & 0.244 & $0.082-0.721$ \\
\hline
\end{tabular}

SE: Standard Error; OR: odds ratio; $\mathrm{Cl}$ : Confidence Interval; (level of significance: $\mathrm{p}<0.05$ ).
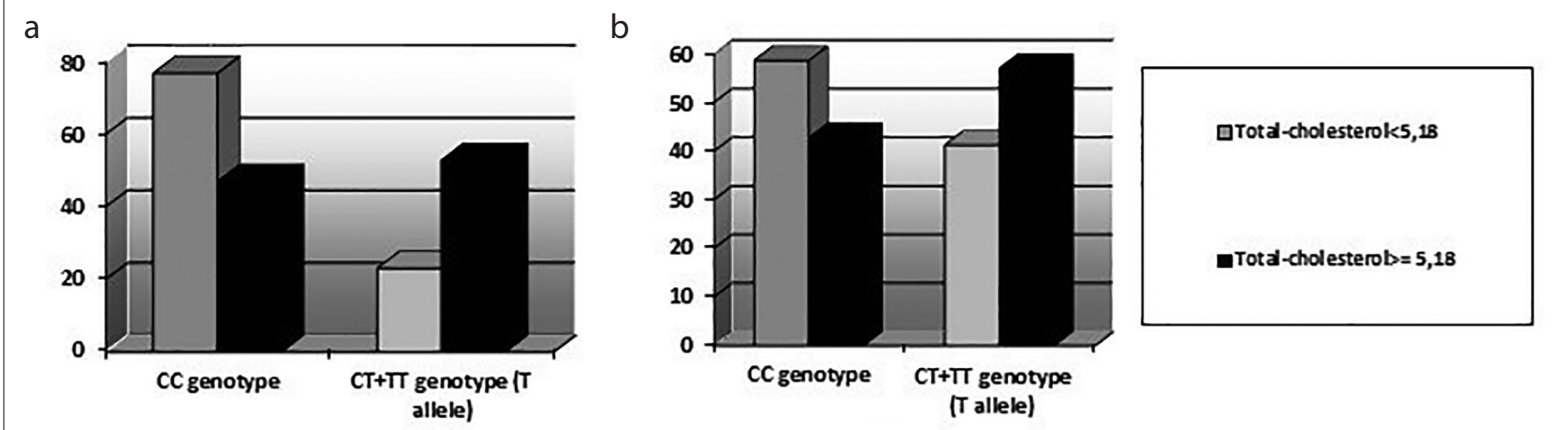

Figure 1. a, b. The association between the CAV1 rs3807990 SNP and hypercholesterolemia in (a) the patient and (b) the control group. * ${ }^{*}$ chi-square $=6.951, p=0.008$.

The effects of the risk parameters that we observed on the development of hypercholesterolemia in the CHD group were further evaluated by Binary logistic regression analysis (Table 6). The Cav-1 rs3807990 T allele, sex, diabetes mellitus, and smoking took part in the categorical variables in the risk analysis for hypercholesterolemia. As a result, it was confirmed that the Cav-1 rs3807990 variation was a risk of hypercholesterolemia in the patient group using logistic regression analysis $(p=0.011)$.

\section{DISCUSSION}

Endothelial dysfunction is associated with cardiovascular risk factors like dyslipidemia, arterial hypertension, hyperglycemia, and diabetes mellitus (Foy and Grant 2007; Hadi and Suwaidi 2007; Lahera et al. 2007). Reduction of nitric oxide (NO) bioavailability underlies on the basis of the endothelial dysfunction (Drab et al. 2001). NO, synthesized from L-arginine by eNOS enzyme in the endothelial cell membrane, is an important factor blocking the atherosclerosis pathogenesis (Blair et al. 1999; Foy and Grant 2007). Several studies examined the effects of the eNOS gene variations on endothelial dysfunction and atherosclerosis pathogenesis in eNOS gene-deficient mice. Absence of the eNOS gene was shown to lead to lack of EDRF (Endothelial-derived releasing factor) activity, hypertension (Razani et al. 2001), leukocyte-endothelial adhesion (Hingorani et al. 1999), increment of platelet aggregation (Casas et al. 2004), vascular smooth muscle cell proliferation (Razani et al. 2001; Fedele et al. 2013), inclination to thrombosis, stroke (Colombo et al. 2002) and atherosclerosis (Shyu et al. 2017).

The eNOS enzyme activity is transcriptionally regulated by interaction with the presence of the substrate, calcium, calmodulin, enzyme cofactors such as FAD, FMN, NADPH, BH4 and with proteins such as Hsp90 and caveolins in various steps (Atochin et al. 2007). Direct interaction of eNOS and caveolin-1 inhibits the eNOS activity. It was shown in studies on mice lacking the Cav-1 gene that the eNOS activity was increased due to the lack of inhibition that should have been created by the interaction between Cav-1 and eNOS (Granath et al. 2001; Karvonen et al. 2002).

Much is known about the association of the NOS3 rs1799983 (Glu298Asp) genotypes with the risk of atherosclerotic coronary events in humans, but the results are controversial. Many studies have suggested a relationship between this gene variation and cardiovascular risk (Huang et al. 1995; Huang et al. 1996; Lefer et al. 1999). In a meta-analysis including 26 studies and a total of 23028 samples, Casas et al. (2004) suggested that the risk of ischemic heart disease might be high in individuals with NOS3 Asp298 and intron-4a homozygous genotypes. However, some studies yielded conflicting results (Huang 2000). Also, in our study, the NOS3 genotype distribution was similar between the study groups ( $p>0.05)$. These different findings might be due to ethnic differences between populations and interactions between the G894T polymorphism and other polymorphisms. Additionally, these findings caused by other factors determining the activity of the eNOS enzyme may show a difference in various populations. When we examined the effects of NOS3 rs1799983 variant on biochemical parameters such as serum lipid profile and blood pressure, we also found no significance between individuals with different genotypes in both groups. In the control group, BMI was observed higher in TT genotype carriers than in GT and GG genotype carriers. As a result of this study, we determined that the NOS3 rs1799983 polymorphism individually could not lead to CHD or its risk factors. 
There are only a few studies in the literature that have examined the NOS3 and Cav-1 gene variations in cardiovascular diseases (Grilo et al. 2006; Joshi et al. 2007; Shyu et al. 2017). It was reported that the Cav-1/NOS3 complex is dissociated to a notably greater extent in the common Glu/Glu ECs than in the Asp variants (Joshi et al. 2007). They suggested that the NOS3 Glu298Asp variation altered caveolar localization and impaired response to shear in human endothelium. Shyu et al. suggested that the minor alleles of the NOS3 rs1799983 G>T, CAV1 rs3807987 G>A and rs7804372 T>A are associated with the increased risk of large artery atherosclerotic stroke among Han Chinese (Shyu et al. 2017). Moreover, Grilo et al. (2006) showed an association between the Cav-1 rs3807990 mutant T allele and high systolic blood pressure, while they did not find any association with serum lipids and lipoprotein levels in their study. They also suggested that there was no gene-gene interaction between the NOS3 and Cav1 genes with regard to metabolic syndrome in hypertensive patients. However, Razani et al. (2001) have determined that Cav1 - / - mice had higher plasma triglyceride levels compared to mice with normal genotype. Frank et al. (2006) investigated the relationship between Cav-1 and cellular cholesterol homeostasis and found that the Cav-1 molecule had a minimal effect on HDL and apolipoprotein A-mediated cholesterol efflux. They also found that the Cav-1 molecule had a crucial effect on the cellular cholesterol homeostasis regulation (Hassan et al. 2004). Smart et al. (1996) similarly suggested that the Cav-1 molecule may be an intracellular cholesterol raft. Formation of Caves and the expression of the Cav-1 protein depend on cholesterol. Caveolin proteins also take a hand in the intracellular cholesterol balance (Chen et al. 1996; Lusis 2000). Cav-1 protein has been shown to interact with SCP-2, which is responsible for the newly synthesized cholesterol delivery from the endoplasmic reticulum to the cell membrane (Chen et al. 1996). Also, Caves function in the process of taking up excess free cholesterol released to plasma into HDLs, the reverse transport of cholesterol, and also the removal of cholesterol esters from plasma (Frank et al. 2004). Our findings confirm that caveolin-1 may have an effect on serum lipid/lipoprotein levels. In our study, BMI was higher in controls with the Cav-1 rs3807990 CT genotype than the $\Pi$ genotype $(p=0.046)$ and the normal $C$ allele was observed to be correlated with low diastolic blood pressure $(p=0.014)$.

Serum total-C levels have been shown to be higher in patients with both the CT genotype $(p=0.008)$ and the T allele (TT genotype + CT genotype) $(p=0.017)$ compared to the CC genotype. Therefore, our results indicate that the Cav-1 rs3807990 rare T allele may contribute to the high total $-C(p=0.017)$ levels in patients with CHD.

We also determined that the CAV1 rs3807990 rare T allele is associated with hypercholesterolemia (serum total-C $>5.18$ $\mathrm{mmol} / \mathrm{L})(\mathrm{p}=0.008)$. In addition, logistic regression analysis confirmed the Cav-1 rs3807990 T allele was a significant risk factor in the development of hypercholesterolemia in CHD subjects. In this context, our study findings also support the association between serum cholesterol levels and the Cav-1 gene variations. Moreover, we investigated the combined effects of the NOS3 and Cav-1 gene polymorphisms in the present study. In CHD patients who had both the Cav-1 rs3807990 rare T allele and the NOS3 rs1799983 rare T allele, the serum HDL-C level was found to be higher in the than the Cav-1 rs3807990 common CC/ NOS3 rs1799983 common GG genotype carriers (1.12 \pm 0.12 vs. $1.01 \pm 0.22, p=0.013)$. However, this association needs to be verified in larger study groups. We believe that our findings will be more meaningful and more concrete in a study group on a wider scale, and will guide the future work in this context.

The limitation of our study was the relatively small study groups $(n=177)$. Secondly, some effects of Cav-1 polymorphisms on serum lipid levels may be masked because the individuals in the patient group received statin therapy in this study, Therefore, we suggest that the effects of Cav-1 gene variations will be more definitive in future studies in which we will investigate the effect of Cav-1 gene polymorphisms on serum lipid levels in patients with CHD receiving with and without statin therapy.

As a conclusion, a better understanding of endothelial dysfunction in the pathogenesis of atherosclerosis is essential for the development of new treatment modalities. Therefore, we investigated the critical variations in NOS3 and Cav-1 genes in this study in order to determine the relations between the $\mathrm{CHD}$ risk factors and $\mathrm{NO}$ production in the endothelial function process. Our study indicated that the Cav-1 rs3807990 T allele may be one of the risk factors for the development of hypercholesterolemia and coronary heart disease.

Ethics Committee Approval: This study protocol was approved by the Ethics Committees of the Istanbul Faculty of Medicine, Istanbul University (approval number:2011/1276-643, date: 27th July, 2013).

Informed Consent: All participants received medical approval from their personal physicians and gave written, informed consent prior to giving their blood sample. This study protocol was arranged according to the World Medical Association Declaration of Helsinki "Ethical Principles for Medical Research Involving Human Subjects".

Peer-review: Externally peer-reviewed.

Author Contributions: Concept - H.Y.A., S.I.; Design - H.Y.A., Z.B.; Supervision - H.Y.A.,O.Ö., Z.B.; Resource - Z.B.; Materials - Z.B., S.I., Ö.K.G.i Data Collection and/or Processing - E.C., S.I., A.P.E.; Analysis and/or Interpretation - H.Y.A., O.Ö., E.C.; Literature Search - S.I., A.P.E., Ö.K.G.; Writing - H.Y.A., S.I., A.P.E., Ö.K.G; Critical Reviews - O.Ö., Z.B.

Conflict of Interest: The authors have no conflict of interest to declare.

Financial Disclosure: The present work was supported by Istanbul University Scientific Research Project Funds. Project No: 37310.

\section{REFERENCES}

- $\quad$ Atochin DN, Wang A, Liu VW, Critchlow JD, Dantas AP, Looft-Wilson R, Murata T, Salomone S, Shin HK, Ayata C, Moskowitz MA, Michel T, Sessa WC, Huang PL (2007). The phosphorylation state of eNOS modulates vascular reactivity and outcome of cerebral ischemia in vivo. J Clin Invest 117: 1961-1967. [CrossRef]

- $\quad$ Blair A, Shaul PW, Yuhanna IS, Conrad PA, Smart EJ (1999). Oxidized low-density lipoprotein displaces endothelial nitric-oxide synthase (eNOS) from plasmalemmal caveolae and impairs eNOS activation. J Biol Chem 274: 32512-32519. [CrossRef]

- Carey RM, Schoeffel CD, Gildea JJ, Jones JE, McGrath HE, Gordon LN, Park MJ, Sobota RS, Underwood PC, Williams J, Sun B, Raby B, Lasky-Su J, Hopkins PN, Adler GK, Williams SM, Jose PA, Felder RA 
(2012). Salt sensitivity of blood pressure is associated with polymorphisms in the sodium-bicarbonate cotransporter. Hypertension 60: 1359-1366. [CrossRef]

- Casas JP, Bautista LE, Humphries SE, Hingorani AD (2004). Endothelial nitric oxide synthase genotype and ischemic heart disease: meta-analysis of 26 studies involving 23028 subjects. Circulation 109: 1359-1365. [CrossRef]

- Chen PF, Tsai AL, Berka V, Wu K (1996). Endothelial nitric-oxide synthase evidence for bidomain structure and successful reconstitution of catalytic activity from two separate domains generated by a baculovirus expression system. J Biol Chem 271: 14631-14635. [CrossRef]

- Chen S, Wang C, Wang X, Xu C, Wu M, Wang P, Tu X, Wang QK (2015). Significant Association between CAV1 Variant rs3807989 on 7 p31 and Atrial Fibrillation in a Chinese Han Population. J Am Heart Assoc 4: e001980. [CrossRef]

- Colombo MG, Andreassi MG, Paradossi U, Botto N, Manfredi S, Masetti S, Rossi G, Clerico A, Biagini A (2002). Evidence for association of a common variant of the endothelial nitric oxide synthase gene ( $\mathrm{Glu}^{298} \rightarrow$ Asp polymorphism) to the presence, extent, and severity of coronary artery disease. Heart 87: 525-528. [CrossRef]

- Conde MC, Ramirez-Lorca R, Lopez-Jamar JM, Molero E, RamirezArmengol JA, Moreno Nogueira JA, Pascual MH, Ruiz A, Martin-Cordova CG, Real LM, Royo JL (2006). Genetic analysis of caveolin-1 and eNOS genes in colorectal cancer. Oncol Rep 16: 353-359. [CrossRef]

- Couet J, Li S, Okamoto T, Ikezu T, Lisanti MP (1997). Identification of peptide and protein ligands for the caveolin-scaffolding domain. Implications for the interaction of caveolin with caveolaeassociated proteins. J Biol Chem 272: 6525-6533. [CrossRef]

- Drab M, Verkade P, Elger M, Kasper M, Lohn M, Lauterbach B, Menne J, Lindschau C, Mende F, Luft FC, Schedl A, Haller H, Kurzchalia TV (2001). Loss of caveolae, vascular dysfunction, and pulmonary defects in caveolin-1 gene-disrupted mice. Science 293: 2449-2452. [CrossRef]

- Fedele F, Mancone M, Chilian WM, Severino P, Canali E, Logan S, De Marchis ML, Volterrani M, Palmirotta R, Guadagni F (2013). Role of genetic polymorphisms of ion channels in the pathophysiology of coronary microvascular dysfunction and ischemic heart disease. Basic Res Cardio/ 108: 387. [CrossRef]

- Frank PG, Lisanti MP (2004). Caveolin-1 and caveolae in atherosclerosis: differential roles in fatty streak formation and neointimal hyperplasia. Curr Opin Lipido/ 15: 523-529. [CrossRef]

- Frank PG, Cheung MW, Pavlides S, Llaverias G, Park DS, Lisanti MP (2006). Caveolin-1 and regulation of cellular cholesterol homeostasis. Am J Physiol Heart Circ Physio/ 291: H677-H686. [CrossRef] Freedman JE, Sauter R, Battinelli EM, Ault K, Knowles C, Huang PL, Loscalzo J (1999). Deficient platelet derived nitric oxide and enhanced hemostasis in mice lacking the NOSIII gene. Circ Res 84: 1416-1421. [CrossRef] Foy CA, Grant PJ (1997). Genes and the development of vascular disease. Postgrad Med J 73: 271-278. [CrossRef]

- Granath B, Taylor RR, Van Bockxmeer FM, Mamotte CD (2001). Lack of evidence for association between endothelial nitric oxide synthase gene polymorphisms and coronary artery disease in the Australian Caucasian population. J Cardiovasc Risk 8: 235-241. [CrossRef]

- Grilo A, Fernandez ML, Beltrán M, Ramirez-Lorca R, González MA, Royo JL, Gutierrez-Tous R, Morón FJ, Couto C, Serrano-Rios M, Saez ME, Ruiz A, Real LM (2006). Genetic analysis of CAV1 gene in hypertension and metabolic syndrome. Thromb Haemost 95: 696-701. [CrossRef]

- Hadi HAR, Suwaidi JA (2007). Endothelial dysfunction in diabetes mellitus. Vasc Health Risk Manag 3: 853-876.

- Hassan GS, Jasmin JF, Schubert W, Frank PG, Lisanti MP (2004). Caveolin-1 deficiency stimulates neointima formation during vascular injury. Biochemistry 43: 8312-8321. [CrossRef]

- Hingorani AD, Liang CF, Fatibene J, Lyon A, Monteith S, Parsons A, Haydock S, Hopper RV, Stephens NG, O'Shaughnessy KM, Brown MJ (1999). A Common Variant of the Endothelial Nitric Oxide Synthase (Glu2983Asp) Is a Major Risk Factor for Coronary Artery Disease in the UK. Circulation 100: 1515-1520. [CrossRef]
Huang PL, Huang Z, Mashimo H, Bloch KD, Moskowitz MA, Bevan JA, Fishman MC (1995). Hypertension in mice lacking the gene for endothelial nitric oxide synthase. Nature 377: 239-242. [CrossRef] Huang PL (2000). Lessons learned from nitric oxide synthase knockout animals. Semin Perinato/ 24: 87-90. [CrossRef]

Huang Z, Huang PL, Ma J, Meng W, Ayata C, Fishman MC, Moskowitz MA (1996). Enlarged infarcts in endothelial nitric oxide synthase knockout mice are attenuated by nitro-L-arginine. J Cereb Blood Flow Metab 16: 981-987. [CrossRef]

Joshi MS, Mineo C, Shaul PW, Bauer JA (2007). Biochemical consequences of the NOS3 Glu298Asp variation in human endothelium: altered caveolar localization and impaired response to shear. FASEB J 21: 2655-2663. [CrossRef]

- Ju H, Zou R, Venema VJ, Venema RC (1997). Direct interaction of endothelial nitric-oxide synthase and caveolin-1 inhibits synthase activity. J Biol Chem 272: 18522-18525. [CrossRef]

- Karvonen J, Kauma H, Kervinen K, Rantala M, Ikäheimo M, Päivänsalo M Savolainen MJ, Kesäniemi YA (2002). Endothelial nitric oxide synthase gene Glu298Asp polymorphism and blood pressure, left ventricular mass and carotid artery atherosclerosis in a population-based cohort. J Intern Med 251: 102-110. [CrossRef] Lahera V, Goicoechea M, de Vinuesa SG, Miana M, de las Heras N, Cachofeiro V, Luño J (2007). Endothelial dysfunction, oxidative stress and inflammation in atherosclerosis: beneficial effects of statins. Curr Med Chem 14: 243-248. [CrossRef]

- $\quad$ Lefer DJ, Jones SP, Girod WG, Baines A, Grisham MB, Cockrell AS, Huang PL, Scalia R (1999). Leukocyte-endothelial cell interactions in nitric oxide synthase-deficient mice. Am J Physio/ 276: H1943-H1950. [CrossRef] Lusis AJ (2000). Atherosclerosis. Nature 407: 233-241. [CrossRef] Marsden PA, Heng HH, Scherer SW, Stewart RJ, Hall AV, Shi XM, Tsui LC, Schappert KT (1993). Structure and chromosomal localization of the human constitutive endothelial nitric oxide synthase gene. J Bio/ Chem 268: 17478-17488.

Puglielli L, Rigotti A, Greco AV, Santos MJ, and Nervi F (1995). Sterol carrier protein-2 is involved in cholesterol transfer from the endoplasmic reticulum to the plasma membrane in human fibroblasts. J Biol Chem 270: 18723-18726. [CrossRef]

- Razani B, Engelman JA, Wang XB, Schubert W, Zhang XL, Marks CB, Macaluso F, Russell RG, Li M, Pestell RG, Di Vizio D, Hou H Jr, Kneitz B, Lagaud G, Christ GJ, Edelmann W, Lisanti MP (2001). Caveolin-1 null mice are viable but show evidence of hyperproliferative and vascular abnormalities. J Biol Chem 276: 38121-38138. Razani B, Combs TP,Wang XB, Frank PG, Park DS, Russell RG, Li M, Tang B, Jelicks LA, Scherer PE, Lisanti MP (2001). Caveolin-1 deficient mice are lean, resistant to diet-induced obesity, and show hyper-triglyceridemia with adipocyte abnormalities. J Bio/ Chem 277: 8635-8647. [CrossRef] Schwencke C, Schmeisser A, Walter C, Wachter R, Pannach S, Weck B, Braun-Dullaeus RC, Kasper M, Strasser RH (2005). Decreased Caveolin-1 in atheroma: loss of antiproliferative control of vascular smooth muscle cells in atherosclerosis. Cardiovasc Res 68: 128-135. [CrossRef]

- $\quad$ Shyu HY, Chen MH, Hsieh YH, Shieh JC, Yen LR, Wang HW, Cheng CW (2017). Association of eNOS and Cav-1 gene polymorphisms with susceptibility risk of large artery atherosclerotic stroke. PLOS One 12: e0174110. [CrossRef]

Smart EJ, Ying Y, Donzell WC, Anderson RG (1996). A role for caveolin in transport of cholesterol from endoplasmic reticulum to plasma membrane. J Bio/ Chem 271: 29427-29435. [CrossRef]

Venema RC, Sayegh H, Kent JD, Harrison DG (1996). Identification, characterization and comparison of the calmodulin-binding domains of the endothelial and inducible nitric oxide synthases. J Biol Chem 271: 6435-6440. [CrossRef]

Williams TM, Lisanti MP (2004). The caveolin proteins. Genome Bio/ 5: 214. [CrossRef]

Yoshimura M, Yasue H, Nakayama M, Shimasaki Y, Sumida H, Sugiyama S, Kugiyama K, Ogawa H, Ogawa Y, Saito Y, Miyamoto Y, Nakao K (1998). A missense glu298-to-asp variant in the endothelial nitric oxide synthase gene is associated with coronary spasm in the Japanese. Hum Genet 103: 65-69. [CrossRef] 